\title{
No Effect of Writing Advice on Reading Comprehension
}

\author{
Balling, Laura Winther
}

Document Version

Accepted author manuscript

Published in:

Journal of Technical Writing and Communication

DOI:

$10.1177 / 0047281617696983$

Publication date:

2018

License

Unspecified

Citation for published version (APA):

Balling, L. W. (2018). No Effect of Writing Advice on Reading Comprehension. Journal of Technical Writing and Communication, 48(1), 104-122. https://doi.org/10.1177/0047281617696983

Link to publication in CBS Research Portal

\section{General rights}

Copyright and moral rights for the publications made accessible in the public portal are retained by the authors and/or other copyright owners and it is a condition of accessing publications that users recognise and abide by the legal requirements associated with these rights.

Take down policy

If you believe that this document breaches copyright please contact us (research.lib@cbs.dk) providing details, and we will remove access to the work immediately and investigate your claim. 


\section{No Effect of Writing Advice on Reading Comprehension Laura Winther Balling \\ Journal article (Accepted manuscript)}

CITE: Balling, L. W. (2018). No Effect of Writing Advice on Reading Comprehension. Journal of Technical Writing and Communication, 48(1), 104-122. D0I: 10.1177/0047281617696983

Copyright (ㅇ The Authors 2017. Reprinted by permission of SAGE Publications.

DOI: https://doi.org/10.1177/0047281617696983

Uploaded to Research@CBS: December 2018 
No Effect of Writing Advice on Reading Comprehension

\begin{abstract}
This article considers text comprehension through the integrated perspectives of language processing research and practical writing advice as expressed in writing guides and language policies. Such guides for instance include advice to use active constructions instead of passives and sentences instead of nominalisations. These recommended and problem constructions and two other contrasts were investigated in an eye-tracking experiment where 27 students read four authentic texts where the target constructions had been manipulated. A mixed-effects regression analysis showed no difference between recommended and problem constructions, while several control variables were significant. This result indicates that the linguistic manipulations are not in themselves crucial to text comprehension, and it is hypothesised that the central aspect for text comprehension is how the linguistic manipulations support cohesion and coherence in the text.
\end{abstract}

\title{
Introduction
}

As many societies and cultures become increasingly literate, it becomes increasingly important - and interesting - to consider what kind of writing makes for optimal comprehension. There are many possible perspectives on this, but integration between them is too rare. The purpose of this article is to integrate two perspectives, namely the research field of language processing with the perspective of writers and writing teachers as expressed in writing guides and language policies. This integration is implemented in an eye-tracking experiment which investigates the processing of those constructions recommended in writing guides in comparison to those the guides advise against (referred to as recommended and problem constructions in the remainder of this article). Eye tracking allows us to observe 
precisely which words and constructions take time during reading, and thus provides us with an objective measure of some aspects of reading comprehension, though not all aspects, as will be discussed. As such, the results of such an investigation are of interest to writers who want their choice of constructions to be guided by knowledge of how readers process them, and to teachers who want their students to write for optimal comprehension. The constructions investigated are relevant to both technical and general writing.

\section{Background}

\section{Problem and recommended constructions}

Writing guides and language policies (e.g. Federal Plain Language Guidelines, 2011; Rozakis, 2000; Sorenson, 2010; Williams, 2005) tend to focus on relatively concrete rules such as "Avoid passives!" (a version of which is also found in the submission guidelines for Journal of Technical Writing and Communication),"Avoid nominalisations!" and "Avoid reduced relative clauses!”. The application of such rules is supposed to make texts easier to understand and make the sender seem more approachable. However, evidence on how these rules affect text comprehension, and on how they interact with other aspects of comprehension, is scarce.

Of these three main problem constructions, passives have received the most research attention, probably due to the important role of the active/passive contrast in generative linguistics (starting with Chomsky, 1957). However, the processing literature is inconclusive: for sentence comprehension, disadvantages for passive constructions in early reports (e.g. Miller \& McKean, 1964) were shown to be restricted to reversible passives by Slobin (1966), and a later study even reported advantages for passives (Carrithers, 1989). In language production, there is some evidence that passives may be preferred for certain patterns of animacy of the noun phrases in the sentence (e.g. Ferreira, 1994, but not Seoane, 2009). In 
addition to being inconclusive, the evidence on passive constructions is problematic for the present purposes because sentences are read out of context, whereas in relation to text comprehension, the context and coherence with that context is central.

Two other types of problem constructions, nominalisations and reduced relative clauses, are advised against because information is assumed to be packed more densely than in the alternative constructions that writing guides recommend. This is completely obvious for reduced relative clauses where the syntactic relation is less explicit than for full relative clauses. For nominalisations, however, the contrast in density between nominalised problem constructions and the recommended clausal constructions seems to vary more from construction to construction. Among the nominalisations in the current experiment (more detail below), for instance, it seems obvious that the recommended construction "whether you are eligible to..." is less dense than the problem construction "your eligibility", while the difference is less clear for a case like the recommended verbal construction "that costs less" compared with the problem nominal construction "of lower cost". The actual effect of these constructions on comprehension are underexplored, though Spyridakis \& Isakson (1998) found that recall of important ideas was better for a text with fewer nominalisations.

\section{Previous experimental work on writing advice and reading comprehension}

As mentioned, investigations of the actual processing of recommended and problem constructions are rare. One exception to this is the experiment reported by Balling (2013a), which the current article builds on. Balling used eye tracking to compare the processing of problem and recommended constructions during reading of authentic texts in Danish. The eye-tracking method allows researchers to establish how long readers gaze on relevant constructions, with long gaze times indicating relative difficulty. With a sample of high- 
quality texts and a group of highly proficient readers, Balling found no reliable differences between recommended and problem constructions.

One possible reason for the null effect of writing advice is that the target texts were of relatively high quality. This matters because high-quality texts generally exhibit relatively high cohesion, allowing a coherent textbase and situation model to be established by readers (Kintsch, 1998). The effect of cohesion and coherence has repeatedly been demonstrated by researchers associated with the Coh-metrix tool for computing cohesion and coherence metrics for written and spoken texts (e.g. McNamara et al., 1996; McNamara, Crossley, \& McCarthy, 2010), but it is less easily translated into hard and fast rules of the type that is preferred in writing guides, language policies and writing crash courses.

Another possible explanation for the lack of an effect is that the readers in the Balling (2013a) study were highly proficient, a mixture of academically high-achieving high school students and university students. It is possible that the advice given by writing guides has a greater impact on reading for less proficient readers, making it relevant to investigate less proficient reading. This could be done in two ways, either by changing the participants to a group of generally less proficient readers, or by changing the language and investigating reading in the readers' L2 where they are less proficient. In the present study, the second approach was adopted, mainly because the experiment aims at investigating linguistic manipulations with as precise a focus as possible, making it desirable to use participants with relatively good decoding skills. In addition, it is interesting to investigate these phenomena in L2 English which is so frequently read in professional contexts, in Denmark and across the globalised world.

\section{The current study}


The experiment reported below investigated how 27 Danish high-school students with L2 English read constructions of the type that writing guides recommend as compared to constructions of the type that are advised against, in their L2. The participants were eyetracked while they were reading four authentic texts containing a variety of recommended and problem constructions. The eye-tracking method gives a straightforward but also rather mechanistic measure of comprehension, namely the gaze time spent on the relevant constructions. However, the experimental set-up was designed to encourage a deeper level of comprehension than in Balling (2013a) where comprehension was indexed in a rather superficial way, through one, relatively easy two-choice question per text. In the present experiment, deeper comprehension was encouraged by setting a frame for reading all four texts that related to the participants themselves, by asking them to imagine that they were looking for information needed when planning a gap year in the UK, and by asking two openended comprehension questions per text.

The most frequent constructions investigated in the experiment were nominalisations compared with sentential constructions, reduced compared with full relative clauses and active sentences compared with passive (see below and Table 1 for more detailed description of the items).

\section{Method}

\section{Texts, Items, and Comprehension Frame}

The participants in the experiment read texts that were presented within the comprehension frame of the participants imagining that they were planning a gap year in the UK and searching for information about taxation, health care, banking, and accommodation. Four text extracts were selected to fit this frame. They were extracts from a guidance about tax on foreign income from Her Majesty's Revenue \& Customs, from a text about NHS 
charges for people from abroad from the webpage of Citizens' Advice, from a text about the Financial Services Compensation Scheme from Barclay's Bank, and from a disclaimer on the website of the estate agency portal net-lettings.co.uk. Obviously, these texts do not constitute the sum of relevant information for a person planning a gap year, but they all fit comfortably within that frame.

Each participant read each text once, either in its original version or in a revised version where problem constructions were changed to recommended constructions and vice versa. Changes were only made if they did not negatively affect the coherence of the text. Both original and revised texts thus contained both kinds of constructions, so it was not the case that one version was globally of much higher quality than the other. Instead, all texts appeared as coherent and well-written texts. The revised texts were thoroughly checked by two English language professionals (in addition to the author) who also compared them to the originals to ensure that the revisions did not make them unnatural or lower in coherence.

The target constructions fell into six different categories, of which two were underrepresented (with only one construction each) and therefore not included in the final analysis reported below. The categories are presented in Table 1, describing both problem and recommended constructions and providing the number of each type that was manipulated in the experiment as well as one example of each.

--- insert Table 1 approx. here ---

The participants' comprehension of the texts was indexed through eight comprehension questions that related the content of the texts to the comprehension frame that was established for the experiment. The questions were a mixture of open and closed questions; no answer options were given. On closer consideration after the experiment, it 
turned out that one of the eight questions could not be unequivocally answered based on the texts, and the answers to this question were therefore not counted as contributing to the final comprehension score.

\section{Participants}

Thirty-two high school students participated in the experiment. The data from five participants were discarded due to poor quality of the eye tracking or, in two cases, the early bilingualism of the participant in question. All remaining participants were late DanishEnglish bilinguals. The participants were high school students enrolled in a programme for academically high-achieving students; they took part in the experiment as part of a day that they spent at Copenhagen Business School where they were introduced to language technology and language processing research. The participants whose data were analysed were aged between 16 and 18 years (mean 17.2 years) and equally distributed between the two genders, with 13 women and 14 men.

\section{Task and Procedure}

The experiment was run on an Eyelink 1000 eye tracker with remote tracking of the right eye at a rate of $500 \mathrm{~Hz}$. The participants were seated approximately $60 \mathrm{~cm}$ from the screen. On arrival, they were instructed orally about the task and then asked to seat themselves in front of the eye tracker so comfortably that they could sit relatively still for the duration of the experiment. A written version of the instructions was then shown on the screen and the participants were allowed to ask questions, before their eyes were calibrated using a nine-point grid. Subsequently, each participant read the four texts, two in the original version and two in the revised version. The texts were presented in random order. Each text was presented on a separate page, allowing readers to move freely in the text (in contrast for 
instance to the single-sentence presentation mode of Balling (2013a) where readers were restricted to considering one sentence at time). This part of the procedure lasted approximately 10 minutes.

After completing the reading, the participants were asked to fill in a questionnaire which included eight comprehension questions and two questions about English language competence. The comprehension questions related the content of the experimental texts to the situational context constructed for the experiment (that of a student planning a gap year in the UK). The English language questions asked participants to rate their general level of English competence and their specific level in reading and comprehending English texts on 7-point Likert scales where 7 corresponded to native language level.

\section{Results}

\section{Data Preparation and Statistical Analyses}

Reading of whole pages of text does not make for ideal eye-tracking data. In the present case, data from three participants had to be discarded and the remaining data were manually cleaned, to make corrections when fixations had drifted systematically, and to delete fixations when there was drift that was not systematic. In cases where it was necessary to delete some fixations on a target construction, all fixations were deleted, and the construction in question for the participant in question was excluded from the analysis. This manual cleaning, including deletion of some fixations, was necessary in order to get data of sufficient quality, but it has two drawbacks: firstly, it makes it impossible to analyse eyetracking measures that rely on the time course of reading. Although no target constructions were included when some of the fixations had been deleted, it in principle becomes indefinable whether fixations belong to the first or a later pass through a construction, when fixations elsewhere in the text had been deleted. It is thus impossible to analyse first pass 
reading times and regression patterns, and the analysis is based on total dwell time only, the sum of all fixations on each target construction. This is not ideal, though total dwell time would be the primary measure of comprehension in any case. Secondly, there was an uneven number of observations per participant and per construction. This is less problematic, since the mixed-effects regression model used for the analysis is relatively robust to unequal numbers of observations (Baayen, Davidson, \& Bates, 2008).

The data were analysed using a mixed-effects regression model as implemented in the lme4 library (Bates, Maechler, Bolker, \& Walker, 2014) in the R language (R Core Team, 2014). In addition to being robust to unequal numbers of observations, a key advantage of mixed regression models is that they allow us to control a number of variables statistically, rather than having to control relevant background variables experimentally. This is absolutely crucial to the meaningful analysis of reading of authentic and semi-authentic texts like the present (for more specific arguments and a non-technical introduction to this analysis approach, see Balling \& Hvelplund, 2015). The regression approach allows us to assess the effect of each variable given all the other variables that are also included in the analysis; this is also what the estimates and p-values in Table 2 and the plots in Figure 1 show.

The dependent variable was total dwell time on target constructions, and the explanatory (or independent) variables were whether the construction was a recommended or a problem construction and, secondarily, which type it was (passive/active, reduced/full relative clause etc., see Table 1). In addition a number of control variables were tested. The length of the construction in characters is a straightforward way of controlling the fact that some constructions are longer than others. The position of the construction in the experiment indexes any differences across an experimental session, position in the text any differences between occurrence early and late in a text, and position in the sentence any differences between constructions that appear at the beginning vs. the end of a sentence. Word familiarity 
and predictability were indexed through the mean frequency of the words in the construction and mean Kneser-Ney smoothed conditional trigram probability (see Balling 2013b for details) of the words in the construction. Finally, the effects of characteristics of the participants were investigated, including their gender, performance on comprehension questions, and self-ratings of general English competence and English reading competence. The dependent variable dwell time and several of the control variables were logarithmically transformed to avoid skewness.

The analysis was conducted in a bottom-up manner, starting with the most controloriented control variables and ending with the central explanatory variables Recommended and Type. Non-significant variables were discarded to arrive at the final model reported in Table 2, with the exception of the central variable Recommended vs. problem construction; this variable was of course what the experiment set out to test and is was therefore retained in the model irrespective of its non-significance. The model summarised in Table 2 is one where data points with large standardised residuals were excluded, in order to meet the requirement that residuals of regression models should be approximately normally distributed; this resulted in the exclusion of $2.0 \%$ of observations and did not substantially change the conclusions.

--- insert Table 2 approximately here ---

Mixed models also have the advantage that dependencies between observations from the same participant and for the same items may be modelled in the random-effects part of the model. With random intercepts, the model allows for the possibility that some participants read more slowly than others, and that some constructions are read more slowly than others, in ways that are not accounted for by the significant predictors in the model. Random slopes 
allow for the possibility that the effect of a given predictor, for instance the mean predictability of the words in the construction, varies between participants in addition to being significant overall. The model summarised in Table 2 includes random intercepts for those variables that are in principle randomly sampled, namely text, construction, and participant, and random levels or slopes for all significant predictors, since they all accounted for some variance.

\section{Recommended and Problem Constructions}

The results of the experiment are summarised in Table 2 and illustrated in Figure 1. The most important result is the complete absence of an effect of whether a construction was recommended or not, as indicated by the non-significant $p$-value of 0.2184 in the final line of the upper box in Table 2. This shows the difference between the problem constructions, which are mapped to the intercept, and the recommended constructions. This non-significant difference is illustrated in the top left panel of Figure 1, which shows that not only was the effect non-significant, the trend also went in the opposite direction of what would be predicted based on writing guides. The same pattern was observed in a model that analysed all constructions, including those that were underrepresented (see Table 1). It is also not the case that there were significant differences for some types and not for others: the effect of type - indicating the difference between the four types passive/active, nominalisation/sentential, reduced/full relative clause and complex/simple words and sentences - was also non-significant and showed no interaction effect. It seems thus that, in itself and with other variables held constant, the difference between recommended and problem constructions does not affect processing time, a result that is further discussed below. As with all null results, it should of course be taken into account that the result offers no direct evidence against an effect of construction type; instead, what we may conclude is 
that there is no evidence for such an effect. However, the fact that the trend goes in the opposite direction than what would be predicted based on writing guides serves to support an interpretation in terms of construction type not in itself being central to processing.

--- insert Figure 1 approximately here ---

\section{Control Variables}

Reassuringly, several of the control variables showed significant effects. These are summarised in Table 2 and illustrated in Figure 1. The largest effect is that of the length of the construction, which is illustrated in the top right panel of Figure 1. This is completely expected: it is well-established that longer constructions are gazed at longer.

The analysis also tested several position variables. The position in experiment and position in text variables were used to investigate whether there was priming, learning or fatigue effects across the entire experiment or within individual texts. This was not the case: both variables were non-significant. The only significant position variable was that of the position in the sentence, which was the ordinal number in the sentence of the first word in the construction. The effect of this variable is illustrated in the bottom left panel of Figure 1 where we see some facilitation for constructions occurring later in the sentence. This is in line with results showing longer reading times for words at the beginning of a sentence, where the scene of the sentence has to be set and where important information often occurs (FrenckMestre, 2005). At first sight, it seems to contrast with the well-known sentence wrap-up effects (Just \& Carpenter, 1980), but in fact constructions occurring later in a sentence often do not occur at the very end and are therefore not necessarily subject to sentence wrap-up effects. 
The final predictor illustrated in Figure 1 is the mean conditional trigram probability of the words in the construction, which was used as an indicator of word predictability. The effect of this variable did not reach full significance $(p=0.0599)$ but it was included in the model because predictability is important to control when analysing selected constructions from authentic texts. As expected, higher predictability correlates with shorter dwell time.

\section{Discussion}

\section{Comprehension, reading speed and reader attitude}

Like the L1 experiment of Balling (2013a), this study of L2 reading showed no difference in reading time between recommended and problem constructions, in general or for specific types of constructions. At first sight, this represents a straightforward failure for common pieces of writing advice like those tested in the experiment, but closer reflection reveals the situation to be more complex than that. Although the writing advice of writing guides, Plain Language guidelines, and language policies is presented as relatively simple rules, these rules in fact unpack into at least three different components: Comprehension, reading speed, and reader attitude.

Comprehension must be the foremost concern, writing advice is after all meant to increase text efficiency which, when considered across text types, must fundamentally be an issue of the reader understanding the text. That being said, comprehension is no simple thing to define or measure; breadth, depth, and level of detail of comprehension vary depending on the text, the reader and the situation. In the present experiment, the reading task was presented in the context of a fictional but not unrealistic situation for the participants of researching some practicalities of spending a gap year in the United Kingdom. This had the purpose of anchoring the comprehension, rather than only dealing with it in superficial terms; hopefully, making for more in-depth comprehension without triggering too slow and detail- 
oriented reading which may be unrepresentative. However, the design does not allow for a very detailed measure of the comprehension that it attempts to generate: right or wrong on seven comprehension questions is a relatively crude measure and indeed did not account for any significant variance in the reading times on target constructions, or in itself exhibit much variation with 20 out of 27 participants achieving a score of 5, 6 or 7 on a 7 -point scale. Seeing an overall effect of comprehension on reading time would perhaps be more likely if texts had been constructed to be either recommended or problem texts, but this would have resulted in reduced ecological validity and a less stringent focus on the target constructions.

The second aspect, reading speed and efficiency, represents a more mechanistic view of text processing, as a decoding process on the part of the reader that the text should support as efficiently as possible. This is straightforwardly measured in the eye-tracking data, which are exactly suited to measuring speed and, through that, ease of reading. There is of course no precise demarcation between decoding and comprehension processes, and increased dwell time is also to some extent a measure of increased comprehension effort. In other words, the absent effect of writing advice on total dwell time is both an absent effect on decoding and comprehension but, as discussed above, there is more to comprehension than what an eyetracking measure can gauge.

The third aspect of writing advice is how the text reflects on the sender. The assumption is for instance that excessive use of passive constructions in a text makes the sender of that text appear distant and (overly) formal. For a full picture of the effect of writing advice, this aspect should also be addressed, but in a very different and most likely qualitative study which is left for future research.

Importantly, the failure to find a difference between recommended and problem constructions in an eye-tracking study only directly relates to the second aspect and indirectly to the first, while the third aspect is ignored. In short, we cannot conclude that writing advice 
is useless, but must conclude that there is no evidence that it affects ease and speed of reading and thus indirectly no evidence of an effect on comprehension. There may still be reasons to give the advice when it targets text reception and reader attitudes towards the sender; the only absolute condition with respect to comprehension is that writing advice should not be counterproductive for comprehension, which is indeed not the case here: the small trend in that direction is clearly non-significant.

\section{First vs. second language processing and reading proficiency}

The decision to run the experiment in the participants' L2 was based on the hypothesis that effects were more likely to show up for less proficient language users, compared to the highly proficient readers that made up the participant group in Balling (2013a). In spite of the reduced proficiency in L2, it remains a possibility that high proficiency is at least part of the reason for the absent effect since the participants in the present experiment rated both their general English skills and their English reading skills highly: on a scale from 1 to 7 where 7 represents native-speaker like, the participants whose data were analysed, had a mean rating of 4.81 on both scales (s.d. 1.13 and 1.20).

\section{Problem constructions and cohesion}

No matter what the explanation for the null result, it remains important to consider writing advice in conjunction with knowledge about discourse processing. Based on evidence for the importance of cohesion from the discourse processing literature, and on experience as a reading and writing teacher, I would argue that the constructions that the writing advice is concerned with - most obviously passives and nominalisations - should be used to support cohesion, especially from sentence to sentence. In other words, a passive construction that allows the sentence to follow the canonical pattern of given before new information (in 
English, Danish and other languages), and is coherent with the previous and following sentences, is likely to be more easily read in a text context than an active that does not; similarly for nominalisations and long or complex constructions. The constructions in the present experiment were purposely manipulated such that they did not result in variations in cohesion, to test the pure effect of the linguistic manipulations. Putting this null effect of the purely linguistic manipulation into practice, the focus should be not on the linguistic manipulation itself but on choosing constructions to support cohesion and coherence. This is a more difficult point to translate into concrete writing advice than a simple rule like "Avoid passives!", but if followed, one that is much more likely to result in increased writing quality and better comprehension.

\section{Avenues for future research}

The current results raise a number of questions that should be pursued in future research. They fall into three groups, corresponding to the three subsections of the discussion above. First, there is the issue of what the writing advice is actually concerned with: comprehension, reading speed and reader attitude. It is essential to consider all three, if possible preferably in conjunction. This would require a study looking at the same texts through several lenses, gauging comprehension through more in-depth measures like recall (e.g. Spyridakis \& Isakson, 1998), reading speed through eye-tracking and reader response through detailed questionnaires or qualitative interviews. The investigation of reader attitude would probably require comparing texts with predominantly problem constructions with texts with predominantly recommended constructions.

Secondly, there is the issue of proficiency. The present experiment used texts in the participants' L2 in order to investigate reduced proficiency, relative to the L1 study of Balling (2013a), but found no increased effect of the writing advice on comprehension for 
this situation of reduced proficiency. However, it may still be the case that lower-proficiency readers benefit more from texts that implement writing advice. In order to investigate this, the reading of readers of overall lower proficiency should be studied. To do this properly, it would be necessary to include a battery of tests of reading skill (along the lines, for instance, of Kuperman \& Van Dyke, 2011) and investigate whether the effect of writing advice on reading comprehension varies with reading skill.

The third question that arises concerns the hypothesis that it is not the choice of construction in itself but the fit of the construction with the sentence-to-sentence cohesion. I am currently preparing a study to investigate this, by comparing passive and active sentences that fit the typical given-new information structure of Danish and English vs. passive and active sentences that do not. Constructions that fit the typical information structure support the cohesion of the text, and the clear hypothesis is therefore that the fit to the information structure will affect reading comprehension, while we would predict no effect of the passive/active manipulation, based on the current results and those of Balling (2013a).

\section{Applying the findings in practice}

A null result like the present is often difficult to translate into practical recommendations. However, the fact that no difference is found between recommended and problem constructions in both the current study and that of Balling (2013a) does have practical implications: First of all, the results indicate that avoiding particular constructions, like passives and nominalisations, in itself has no effect on readers' comprehension of both technical and general texts. Secondly, following from this, writing guides and language policies should avoid such simplistic advice, and instead focus more of the roles of the choice of construction on cohesion and coherence. This of course also holds for teachers of writing and language more generally; though I doubt that many experienced teachers would subscribe 
to such simplistic views in the first place, the current results - especially if supported by future research along the lines described above - may contribute to a further nuancing of the advice given to developing writers by their teachers.

\section{Conclusion}

Summing up, the eye-tracking experiment reported in this article investigated whether those constructions that are typically recommended in writing guides are better than those that are advised against in terms of reading time and, by implication, comprehension. This was not the case: the time spent on target constructions did not vary as a function of whether the construction was of a recommended type or not. By contrast, several other variables related to reading comprehension did show an effect on gaze time. Although I argue that reading time is not the only relevant success criterion for the recommendations of writing guides - both reader attitude and those aspects of comprehension not indexed by reading time are also relevant - the lack of effect on reading time does suggest that more nuanced advice is merited.

I hypothesise that the choice of construction should depend on sentence-to-sentence cohesion, and that writing advice should reflect this, though further research on this is necessary, along with investigations of the effect of writing advice on depth of comprehension, on reader attitude and for different levels of reading proficiency. Future research should also aim at further integration of knowledge of writing practices into language processing research and of language processing knowledge into writing practices. This could strengthen both research fields, make for better models of writing, writing teaching, and text comprehension, and ultimately result, we may hope, in better writing.

\section{Acknowledgements}


I am grateful to Barbara Dragsted and Kristian T. Hvelplund for helping me check the experimental texts and to an anonymous reviewer for detailed comments on a previous version of this article. 


\section{References}

Balling, L. W. (2013a). Does Good Writing Mean Good Reading? An Eye-tracking Investigation of the Effect of Writing. Fachsprache, 35(1-2), 2-23.

Balling, L. W. (2013b). Reading authentic texts : What counts as cognate? Bilingualism: Language and Cognition. doi:10.1017/S1366728911000733

Balling, L.W. \& Hvelplund, K.T. 2015. Design and Statistics in Quantitative Translation (Process) Research. Translation Spaces, 4(1), 169-186.

Bates, D. M., Maechler, M., Bolker, B., \& Walker, S. (2014). lme4: Linear mixed-effects models using Eigen and S4. R package version 1.1-7. Retrieved from http://cran.rproject.org/package $=1 m e 4$

Baayen, R. H., Davidson, D., \& Bates, D. H. (2008). Mixed-effects modelling with crossed random effects for subjects and items. Journal of Memory and Language, 59, 390-412.

Carrithers, C. (1989). Syntactic Complexity Does Not Necessarily Make Sentences Harder to Understand. Journal of Psycholinguistic Research, 18(1), 75-88.

Chomsky, N. (1957). Syntactic structures. The Hague: Mouton de Gruyter.

Federal Plain Language Guidelines. (2011). Retrieved from http://www.plainlanguage.gov/howto/guidelines/FederalPLGuidelines/FederalPLGuideli nes.pdf. April 30, 2012.

Ferreira, F. (1994). Choice of Passive Voice Is Affected by Verb Type and Animacy. Journal of Memory and Language 33, 715-736. 
Frenck-Mestre, C. (2005). Eye-movement recording as a tool for studying syntactic processing in a second language: a review of methodologies and experimental findings. Second Language Research, 21, 175-198.

Just, M. A., \& Carpenter, P. A. (1980). A theory of reading: from eye fixations to comprehension. Psychological Review, 87, 329-354.

Kintsch, W. (1998). Comprehension. A paradigm for cognition. Cambridge, UK: Cambridge University Press.

Kuperman, V. \& Van Dyke, J.A. (2011). Effects of individual differences in verbal skills on eye-movement patterns during sentence reading. Journal of Memory and Language, 65, $42-73$.

McNamara, D., Kintsch, E., Songer, N. B., \& Kintsch, W. (1996). Are Good Texts Always Better? Interactions of Text Coherence, Background Knowledge, and Levels of Understanding in Learning From Text. Cognition and Instruction, 14(1), 1-43. doi:10.1207/s1532690xci1401_1

McNamara, D. S., Crossley, S. a., \& McCarthy, P. M. (2010). Linguistic Features of Writing Quality. Written Communication, 27(1), 57-86. doi:10.1177/0741088309351547

Miller, G. A., \& McKean, K. O. (1964). A Chronometric study of some relations between sentences. Quarterly Journal of Experimental Psychology, 16, 297-308.

R Core Team. (2014). R: A Language and Environment for Statistical Computing. Vienna, Austria. Retrieved from http://www.r-project.org/ 
Rozakis, L. (2000). Complete Idiot's Guide to Writing Well. East Rutherford, NJ, USA: Penguin Putnam.

Seoane, E. 2009. Syntactic complexity, discourse status and animacy as determinants of grammatical variation in Modern English. English Language and Linguistics, 13(3), 365-384.

Slobin, D. I. (1966). Grammatical transformations and sentence comprehension in childhood and adulthood. Journal of Verbal Learning and Verbal Behavior, 5, 219-227.

Sorenson, S. (2010). Webster's New World Student Writing Handbook (5th ed.). Hoboken, New Jersey: Webster's New World.

Spyridakis, J. H., \& Isakson, C. S. (1998). Nominalizations vs. denominalizations: do they influence what readers recall? Journal of Technical Writing and Communication, 28, $163-188$.

Williams, J. M. (2005). Style. Ten lessons in clarity and grace (8th ed.). New York: Pearson Longman. 


\section{Appendix}

The four text extracts used on the experiment. All were retrieved in November 2012 and abbreviated to fit on one page while providing information that fit within the comprehension frame. Below, target constructions are within square parentheses and marked with bold, the category of the construction is given in subscript. The first construction inside each set of square parentheses is the one that occurred in the original text.

\section{Text A: Tax on Foreign Income}

This guidance replaces the IR20 Residents and non-residents: Liability to tax in the United Kingdom. Any practices [associated/that were associated] RELATIVE with the IR20 - whether overtly expressed or not - will not apply from 6 April 2009, unless [provided/they are provided] ELLIPSIS for outside the IR20 (in statute law, in case law, in published extra-statutory concession, or in a guidance note). This guidance outlines [our (HM Revenue \& Customs) application and interpretation of/how we (HM Revenue \& Customs) apply and

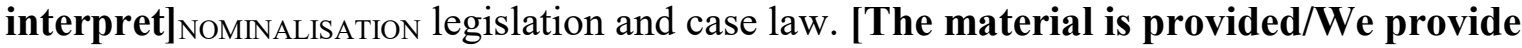
the material] PASSIVE [for your guidance/to guide you] NOMINALISATION. It sets out the main factors [that are taken into account/ taken into account $]_{\text {RELATIVE }}$ based on the rulings of the courts. Whether any section of this general guidance is applicable to you depends on your particular facts, as each set of circumstances will [be different/differ]COMPLEX. It also seeks to give practical examples of what the relevant law means; these are only illustrative examples. Any practices [described/which are described] RELATIVE in this guidance are [subject to periodic review/periodically reviewed] $]_{\text {OMINALISATION }}$ and may subsequently be

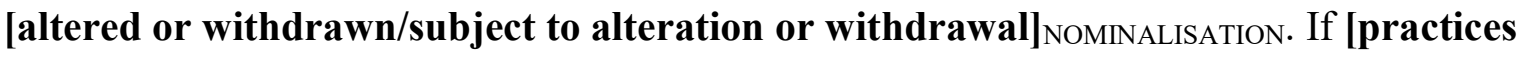
were to be changed or revoked/ we were to change or revoke practices] PASSIVE [this 
would not normally be done/we would not normally do this] PASSIVE retrospectively. You do not need to read this guidance if you live in the UK and pay UK tax on your UK income and chargeable gains and you plan to remain in the UK and either:

- have never received foreign income or foreign chargeable gains or

- have had foreign income or chargeable gains in the past and you paid UK tax on the foreign income or gains in the years when these arose/accrued or

- have had and paid tax on foreign income before coming to live in the UK.

(Source: http://www.hmrc.gov.uk/cnr/hmrc6.pdf)

\section{Text B: NHS charges for people from abroad}

Your entitlement to free NHS treatment depends on [the length and purpose of your

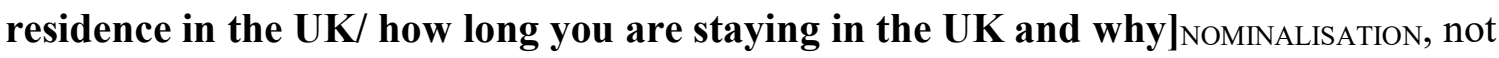
your nationality. There may be charges for some NHS services, for example, your dental treatment, and you may be entitled to help with these charges. [Any free NHS treatment you receive, or any help with NHS costs, does not affect your immigration status/ Your immigration status is not affected by any free NHS treatment you receive, or any help with NHS costs] PASSIVE. If you are entitled to it, you can obtain free treatment immediately. There is no qualifying period. If you have to pay for treatment because you do not meet the residence conditions, this does not count as discrimination. However, you must be [given clear information/informed clearly] $]_{\text {NOMINALISATION }}$ about charges in a way you understand. This could include [providing information/being informed] NOMINALISATION $_{\text {in a foreign }}$ language or an interpreter, if necessary. If you aren't [given clear information/informed

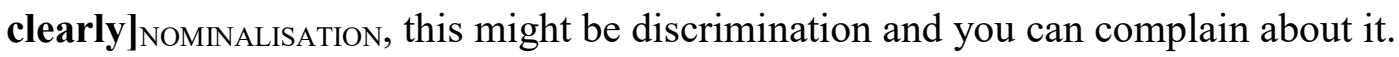


Who can receive all NHS hospital treatment free of charge?

You can get free NHS hospital treatment if you are lawfully entitled to be in the UK and usually live here. This is called being ordinarily resident. You can receive free NHS hospital treatment if you:

1. have [been living legally/had lawful residence] months when you start treatment, and did not come to the UK for private medical treatment.

2. have come to the UK to work, either as an employee or self-employed person.

3. are a student following a course of study which lasts at least six months, or a course that is substantially funded by the UK, Welsh, Scottish or Northern Ireland Governments.

(Source:

http://www.adviceguide.org.uk/england/healthcare_e/healthcare_help_with_health_costs_e/n hs_charges_for_people_from_abroad.htm)

\section{Text C: Important Information about Compensation Arrangements}

We are covered by the Financial Services Compensation Scheme (FSCS). The FSCS can

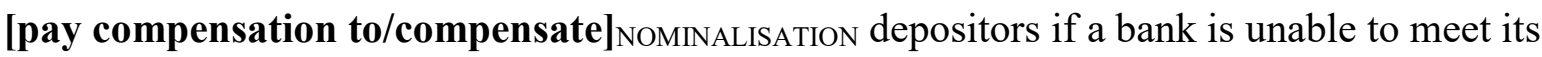
financial obligations. [Most depositors - including most individuals and small businesses - are covered by the scheme/The scheme covers most depositors - including most

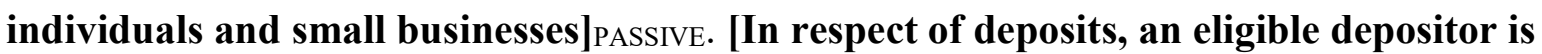
entitled to claim up to $£ 85,000$ /An eligible depositor is entitled to claim up to $£ 85,000$ in

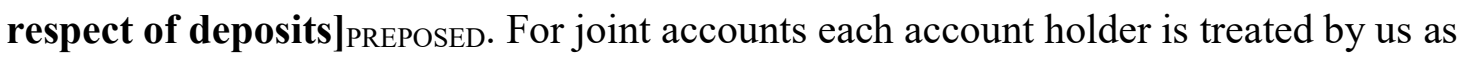
having a claim in respect of their share so, for a joint account [held by two eligible depositors/which is held by to eligible depositors] RELATIVE, the maximum amount that 
could be claimed would be $£ 85,000$ each (making a total of $£ 170,000$ ). The $£ 85,000$ limit [relates/is in relation] accounts with the bank, including their share of any joint account, and not to each separate account. For further information about the scheme (including the amounts [covered/that we

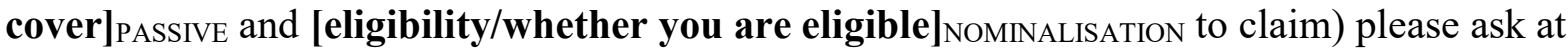
your local branch, refer to the Financial Services Compensation Scheme website or call 020 78927300 or 08006781100 .

(Source:

http://www.barclays.co.uk/Loans/StudentAdditionsaccounttermsandconditions/P1242574410 $\underline{031)}$

\section{Text D: Disclaimer from net-lettings.co.uk}

\section{Rent Guides}

The guideline rents [indicated/that are indicated] RELATIVE on the front pages are, [of

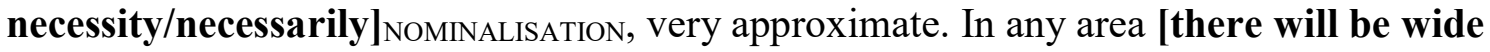
variations/the rent will vary widely $]_{\text {NOMINALISATION }}$ due to factors such as the quality and condition of the accommodation, distance from public transport and shops, local amenities and the general nature of the locale. You may well find accommodation [that costs/of lower cost] NOMINALISATION less than indicated, you will certainly be able to pay more for the premium properties. London is a very large city and [there is a wide variety of accommodation types/accommodation types vary widely] $]_{\text {NOMINALISATION. Local rents }}$ reflect this diversity. In providing simple guides to complex subjects [it is unavoidable that

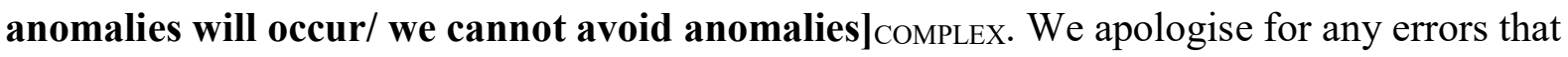
you may come across. 
General

[It is intended that this Web site should/this Web site intends to] COMPLEX [provide

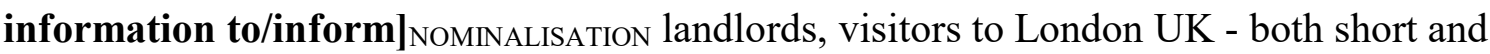
long term - and their agents. Whilst we endeavour to keep the information on this Web site accurate and up-to-date, neither us nor our client agencies [make any guarantee as

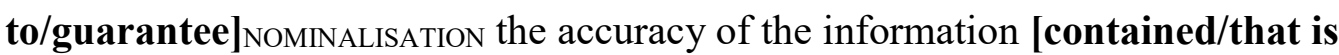
contained $]_{\text {RELATIVE }}$ on this site. This site and the clients [shown/which are shown] RELATIVE on it also explicitly disclaim any responsibility or liability for any losses or damages incurred by any third party as a direct or indirect consequence of any of the information [contained/that is contained $]_{\text {RELATIVE }}$ on this site.

(Source: http://www.net-lettings.co.uk/disclaimer) 
Construction Types and Examples from the Target Texts

\begin{tabular}{|l|l|l|l|}
\hline Problem & Recommendation & n & Example \\
\hline Nominalisation & Verbal construction & 18 & $\begin{array}{l}\text { - is in relation to } \\
+ \text { relates to }\end{array}$ \\
\hline Reduced relative clause & Full relative clause & 8 & $\begin{array}{l}\text { - information contained } \\
+ \text { information that is contained }\end{array}$ \\
\hline Passive verb & Active verb & 6 & $\begin{array}{l}\text { - amounts covered } \\
+ \text { amounts we cover }\end{array}$ \\
\hline $\begin{array}{l}\text { Long or complex words or } \\
\text { sentences }\end{array}$ & Shorter sentences or words & 3 & $\begin{array}{l}\text { - be different } \\
+ \text { differ }\end{array}$ \\
\hline $\begin{array}{l}\text { Preposed adverbial } \\
\text { Elided material }\end{array}$ & Postposed adverbial & $\begin{array}{l}\text { - In respect of deposits, ... } \\
+ \text { in respect of deposits }\end{array}$ \\
\hline
\end{tabular}

Table 1: The categories of constructions investigated in the experiment. Grey categories were not included due to their low incidence in the texts. 
Summary of Mixed-Effects Model of Total Dwell Time on Target Constructions

\begin{tabular}{|l|l|l|l|l|l|}
\hline & Estimate & Std. error & df & $\mathrm{t}$ & $\mathrm{p}$ \\
\hline Intercept & 3.9192 & 0.1926 & 44.67 & 20.3470 & $<0.0001$ \\
\hline Sentence length (log) & 1.0045 & 0.0408 & 40.27 & 24.5450 & $<0.0001$ \\
\hline Position in sentence (log) & -0.1058 & 0.0248 & 41.82 & -4.2590 & 0.0001 \\
\hline Mean trigram probability & -0.0478 & 0.0248 & 49.07 & -1.9260 & 0.0599 \\
\hline Recommended:YES & 0.0502 & 0.0409 & 42.67 & 1.2490 & 0.2184 \\
\hline
\end{tabular}

\begin{tabular}{|l|l|l|l|l|l|l|l|}
\hline Groups & Name & Var. & Std. Dev & \multicolumn{3}{l|}{ Correlations } \\
\hline Construction & Intercept & 0.0117 & 0.1082 & & & \\
\hline Participant & Intercept & 0.2097 & 0.4579 & & & & \\
\hline & Levels: Recommended:YES & 0.0069 & 0.0834 & 0.26 & & & \\
\hline & Slopes: Mean trigram prob & 0.0038 & 0.0619 & 0.36 & 0 & & \\
\hline & Slopes: Sentence length (log) & 0.0118 & 0.1085 & -0.79 & 0.02 & -0.15 & \\
\hline & Slopes: Pos. in sentence (log) & 0.0040 & 0.0632 & -0.91 & -0.4 & -0.61 & 0.52 \\
\hline Text & Intercept & 0.0095 & 0.0976 & & & & \\
\hline Residual & & 0.1282 & 0.3581 & & & & \\
\hline
\end{tabular}

Table 2: Summary of mixed-effects model of total dwell time in the experiment. The fixed effects are in the upper table, random effects in the lower table. The model uses treatment coding with Recommended: NO (i.e. problem constructions) as the reference level; the line "Recommended:YES" tests the difference between the two levels of this predictor. 

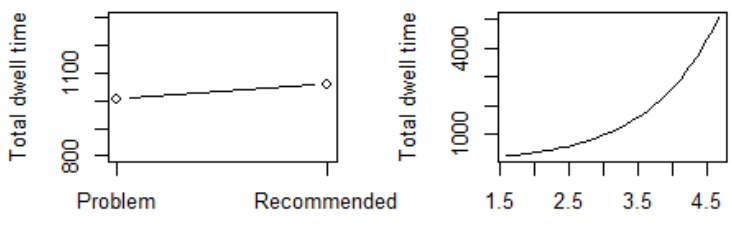

Length in characters $(\log )$
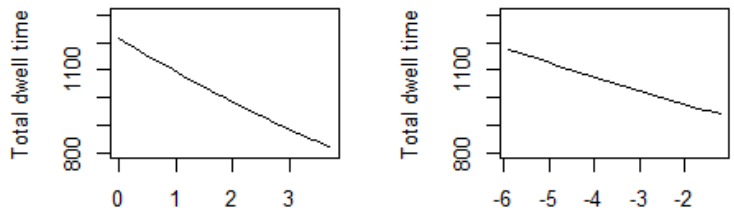

Position in sentence $(\log )$

Mean trigram probabability

Figure 1: Partial effects plot of the predictors included in the final analysis, with the dependent variable total dwell time (back-transformed from the log scale for ease of interpretation) on the vertical axis and one significant predictor on the horizontal axis of each panel. Each panel shows the effect of one predictor with other predictors held constant at their median. Note the different scale for the top right panel, indicating the large effect of length. 